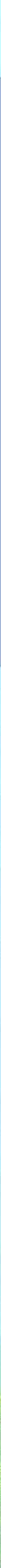




\section{Journal of MATERIALS RESEARCH}

JOURNAL OF MATERIALS RESEARCH (JMR) is an interdisciplinary journal serving the materials research community through publication of original research articles and invited reviews encompassing the synthesis, processing, characterization, properties, and theoretical description of materials.

JMR publishes new research that demonstrates a significant impact or advance of scientific understanding of interest to the materials research community. Engineering studies and applications to commercial products are beyond the scope of $J M R$ and should be submitted elsewhere. Manuscripts that report data without giving an analysis, interpretation, or discussion are only acceptable if the data are sufficiently important that publication is expected to lead to significant new studies or advancements in science or technology.

Manuscripts must be submitted to the Journal of Materials Research electronically via ScholarOne manuscripts, at the following website address: http://mc.manuscriptcentral.com/jmr. Electronic submission expedites the review process and also allows authors to track the status of their manuscripts at any time. Complete instructions are available on the ScholarOne site and authors will be prompted to provide all necessary information.

Manuscripts must be prepared in English, using a word processing program, formatted to fit $81 / 2 \times 11$ in. paper, and saved as .doc or .pdf files. Separate graphics files (.eps and .tif) must be uploaded for each figure. Authors may also upload .xls or .ppt supplemental files as part of the manuscript submission process. All of these files will be converted to .pdf format. Detailed instructions are available on the submission web site. During submission, authors must enter all coauthor names and e-mail addresses. Manuscripts will not be considered for peer review until this information is provided. Authors must also enter manuscript keywords using the $J M R$ keyword list (located on the submission web site). Authors who are not fluent in English must have their manuscript edited for correct English grammar and sentence structure before submission.

Authors are expected to follow the conventional writing, notation, and illustration style prescribed in Scientific Style and Format: the CSE Manual for Authors, Editors and Publishers, 7th edition, 2006. Authors should also study the form and style of printed material in this journal. SI units should be used. Authors should use an identical format for their names in all publications to facilitate use of citations and author indexes.

Manuscripts are accepted with the understanding that they represent original research, except for review articles, and that they have not been copyrighted, published, or submitted for publication elsewhere. Authors submitting manuscripts to JMR who have related material under consideration or in press elsewhere should send a copy of the related material to JMR at the time of submission. While their manuscripts are under consideration at $J M R$, authors must disclose any such related material. To expedite the review process, authors may provide names and contact information for up to four possible reviewers.

Articles are original research reports that include complete, detailed, self-contained descriptions of research efforts. All articles must contain an abstract and section headings.

Commentaries and Reviews: Journal of Materials Researchoccasionally publishes commentaries on topics of current interest or reviews of the literature in a given area. If an author proposes a review, the title, abstract, and a brief outline should be submitted to the Editorial Office via e-mail for prior consultation on the appropriateness of the topic.

Color policy: It is not necessary for authors to indicate that a figure should be displayed in color online. JMR will assume that any author who submits figures in color wants and agrees to their being produced in color online. Figures may be printed in color at the author's request for an additional charge. Color figures must be submitted before the paper is accepted for publication, and cannot be received later in the process. Authors cannot submit two versions of the same figure, one for color and one for black and white; only one version can be submitted. Authors need to carefully consider the following when submitting figures in color that will be published in color online only: 1) The colors chosen must reproduce effectively and the colors should be distinguishable when printed in black and white; 2) The descriptions of figures in text and captions must be sufficiently clear for both online and print copy. When submitting figures to be in color online only, authors should include the phrase $<<$ color online $>>$ in the figure captions. This is the author's responsibility. Authors will see these color figures when viewing their author page proofs on screen. Authors should always print their page proofs in black and white to see how they will appear in print. Authors will NOT be allowed to submit color figures to replace black and white figures in the page proof stage. To maximize the probability that figures will be published in color online and also print as good quality black and white or grayscale graphics, authors are encouraged to follow these figure submission guidelines: 1) Submit a color graphic in Tagged Image File Format (.tif); 2) Submit color graphics with a resolution of at least $300 \mathrm{dpi}(600 \mathrm{dpi}$ if there is text or line art in the figure); 3) Submit color graphics in CMYK format; 4) Submit figures sized to fit the actual column or page width of the journal so that reduction or enlargement is not necessary; 5) Submit multipart figures in one single electronic file.

Copyright $\odot$ 2018, Materials Research Society. All rights reserved. No part of this publication may be reproduced, in any form or by any means, electronic, photocopying, or otherwise, without permission in writing from Cambridge University Press. Policies, request forms and contacts are available at: http://www.cambridge.org/rights/permissions/permission $\mathrm{htm}$. Permission to copy (for users in the USA) is available from Copyright Clearance Center at: http://www.copyright.com, email: info@ copyright.com.

\begin{tabular}{lrrr}
\hline \hline $\begin{array}{l}\text { Journal of Materials Research Subscription Prices (2018) } \\
\text { [includes on-line web access] }\end{array}$ & $\begin{array}{c}\text { USA and } \\
\text { Poss. }\end{array}$ & Non-US & $\begin{array}{c}\text { Online } \\
\text { Only }\end{array}$ \\
\hline $\begin{array}{l}\text { MRS Regular and Student } \\
\text { Members }\end{array}$ & $\$ 287.00$ & $\$ 351.00$ & $\$ 110.00$ \\
\begin{tabular}{l} 
Institutions \\
\hline \hline
\end{tabular} & $\$ 2218.00$ & $\$ 2156.00$ & $\$ 1946.00$ \\
\hline
\end{tabular}

Journal of Materials Research (ISSN: 0884-2914) is published twenty-four times a year by Cambridge University Press, One Liberty Plaza, 20th Floor, New York, NY 10006 for the Materials Research Society. Periodical Postage Paid in New York, NY and additional mailing offices. POSTMASTER: Send address changes to Journal of Materials Research, c/o Journals Dept., Cambridge University Press, One Liberty Plaza, 20th Floor, New York, NY 10006, USA.

Subscriptions, renewals, address changes, and single-copy orders should be addressed to Subscription Fulfillment, Journal of Materials Research, Cambridge University Press, One Liberty Plaza, 20th Floor New York, NY 10006, USA (for USA, Canada, and Mexico); or Cambridge University Press, University Printing House, Shaftesbury Road, Cambridge, CB2 8BS, England (for UK and elsewhere). Allow at least six weeks advance notice. For address changes, please send both old and new addresses and, if possible, include a mailing label from a recent issue. Requests from subscribers for missing journal issues will be honored without charge only if received within six months of the issue's actual date of publication; otherwise, the issue may be purchased at the single-copy price.

Reprints of individual articles in Journal of Materials Research may be ordered. For information on reprints, please contact Cambridge University Press. Reprints of complete back issues older than the prior volume year may be ordered on an individual basis via Cambridge Core. To determine availability, visit the appropriate page for the JMR back issue desired (cambridge.org/jmr).

Individual member subscriptions are for personal use only. 


\section{Journal of}

\section{MATERIALS RESEARCH}

Editor-in-Chief: Gary L. Messing, Ceramic materials, The Pennsylvania State University, USA

Associate Editor: Susmita Bose, Biomaterials, Washington State University, USA

Associate Editor: Jürgen Eckert, Metallic materials, Montanuniversität Leoben, Austria

Associate Editor: Linda S. Schadler, Polymeric materials, University of Vermont, USA

Guest Editors for Focus Issue: Soft Magnetic Materials: Synthesis, Characterization, and Applications

Todd C. Monson, Sandia National Laboratories, USA

Josefina Silveyra, Instituto de Tecnologías y Ciencias de la Ingeniería (INTECIN), Universidad de Buenos Aires - CONICET, Argentina

Enzo Ferrara, Istituto Nazionale di Ricerca Metrologica-INRIM, Italy

Mitra Taheri, Drexel University, USA

2018 Principal Editors:

Torbjörn Thiringer, Chalmers University of Technology, Sweden

Amit Bandyopadhyay, Hard biomaterials, Additive manufacturing, Washington State University, USA

Jinju Chen, Soft materials/thin films, Nanoindentation, Newcastle University, United Kingdom

Xiaobo Chen, Photocatalysis and batteries, University of Missouri-Kansas City, USA

Yang-T. Cheng, Mechanical behavior, Electrochemical energy storage, University of Kentucky, USA

Sung-Yoon Chung, Energy, Electron microscopy, Interface science, KAIST, Korea

Paolo Colombo, Preceramic polymers, Porous ceramics, University of Padova, Italy; The Pennsylvania State University, USA

Franz Faupel, Functional nanomaterials, VPD, Metallic glasses, University of Kiel, Germany

Mathias Göken, Superalloys, Nanomaterials, Nanomechanics, Friedrich-Alexander-Universität Erlangen-Nürnberg, Germany

Amit Goyal, Superconductors, Photovoltaics, 2D materials, Self-assembly, State University of New York at Buffalo, USA

Erik G. Herbert, Nanoindentation, Small-scale mechanical behavior Michigan Technological University, USA

Himanshu Jain, Inorganic glass, Optical, Electrical properties, Lehigh University, USA

C. Robert Kao, Metallic materials, Diffusion and joining, National Taiwan University, Taiwan

Edson Roberto Leite, Materials chemistry, Nanocrystals, Synthesis, Universidade Federal de São Carlos, Brazil

Jörg Löffler, Metallic materials/synthesis and properties, ETH Zurich, Switzerland

Michele Manuel, Phase transformations, Materials design, University of Florida, USA

Michael E. McHenry, Magnetic materials, Carnegie Mellon University, USA

Scott T. Misture, In-situ diffraction, Electrochemically active ceramics, Alfred University, USA
Sarah E. Morgan, Polymer surfaces and interfaces, The University of Southern Mississippi, USA

Paul Muralt, Thin films, Piezoelectric and ferroelectric materials, Ecole Polytechnique Federale de Lausanne, Switzerland

Lakshmi S. Nair, Biomaterials, Tissue regeneration, Drug delivery, University of Connecticut, USA

Akira Nakajima, Photocatalysis, Surface wettability, Ceramic processing, Tokyo Institute of Technology, Japan

Cewen Nan, Ferroelectric, Multiferroic materials, Tsinghua University, China

George M. Pharr, Mechanical behavior, Nanoindentation, Texas A\&M University, USA

Ian M. Reaney, Electroceramics, TEM, Thin films, The University of Sheffield, United Kingdom

Edward M. Sabolsky, Electroceramics, Electrochemistry, Processing, West Virginia University, USA

Winston Schoenfeld, Optical materials, University of Central Florida, USA

Don W. Shaw, Epitaxy, Vapor deposition, Semiconductors, The University of Texas at Dallas, USA

Susan B. Sinnott, Computational materials science, The Pennsylvania State University, USA

Terry M. Tritt, Thermoelectrics, Clemson University, USA

Chongmin Wang, Energy storage, Microscopy, In-situ/operando technique, Pacific Northwest National Laboratory, USA

William J. Weber, Radiation effects, Nuclear ceramics, University of Tennessee; Oak Ridge National Laboratory, USA

Sam Zhang, Thin films/coatings, Nanyang Technological University, Singapore

Yanchun Zhou, Structural ceramics, Electronic structure, Aerospace Research Institute of Materials and Processing Technology, China

Editorial Office: Ellen W. Kracht, Publications Manager, Materials Research Society, Warrendale, $P A$ Linda A. Baker, JMR Editorial Assistant, Materials Research Society, Warrendale, PA Kirby L. Morris, JMR Production Assistant, Materials Research Society, Warrendale, PA Eileen M. Kiley, Director of Communications, Materials Research Society, Warrendale, PA 
Volume 33, Number 15, August 13, 2018

SOFT MAGNETIC MATERIALS: SYNTHESIS, CHARACTERIZATION, AND APPLICATIONS

2119 Introduction

Todd C. Monson,

Josefina Silveyra, Enzo Ferrara,

Mitra Taheri, Torbjörn Thiringer

\section{REVIEW}

2120-2137 Characterization and assessment of the wideband magnetic properties of nanocrystalline alloys and soft ferrites

Enzo Ferrara, Fausto Fiorillo, Cinzia Beatrice, Samuel Dobák, Carlo Ragusa, Alessandro Magni, Carlo Appino

\section{ARTICLES}

2138-2147 Finite element analysis modeling of high voltage and frequency 3-phase solid state transformers enabled by metal amorphous nanocomposites

2148-2155 Effect of annealing on magnetic properties of $\mathrm{Ni}-\mathrm{Mn}-\mathrm{Ga}$ glass-coated microwires

2156-2167 Gram scale synthesis of $\mathrm{Fe} / \mathrm{Fe}_{x} \mathrm{O}_{y}$ core-shell nanoparticles and their incorporation into matrix-free superparamagnetic nanocomposites

2168-2175 Equal channel angular extrusion for bulk processing of Fe-Co-2V soft magnetic alloys, part I: Processing and mechanical properties

2176-2188 Equal channel angular extrusion for bulk processing of Fe-Co-2V soft magnetic alloys, part II: Texture analysis and magnetic properties

2189-2206 Thermal profile shaping and loss impacts of strain annealing on magnetic ribbon cores

2207-2213 Assessment of Fe-Ga-B alloy magnetomechanical behavior

2214-2222 Influence of heat treatment on microstructure, mechanical behavior, and soft magnetic properties in an fcc-based $\mathrm{Fe}_{29} \mathrm{Co}_{28} \mathrm{Ni}_{29} \mathrm{Cu}_{7} \mathrm{Ti}_{7}$ high-entropy alloy

2223-2233 Finite element modeling of nanoscale-enabled microinductors for power electronics

Mst Nazmunnahar, Satoru Simizu, Paul R. Ohodnicki,

Subhashis Bhattacharya,

Michael E. McHenry

Arcady Zhukov, Mihail Ipatov, Juan J. del Val, Paula Corte-León, Julian Gonzalez,

Alexandr Granovsky,

Valentina Zhukova

John Watt, Grant C. Bleier,

Zachary W. Romero,

Bradley G. Hance,

Jessica A. Bierner,

Todd C. Monson, Dale L. Huber

Don F. Susan, Taymaz Jozaghi, Ibrahim Karaman, Jeff M. Rodelas

Andrew B. Kustas,

Joseph R. Michael, Don F. Susan, Ibrahim Karaman, Taymaz Jozaghi

Richard Beddingfield,

Subhashish Bhattacharya,

Kevin Byerly, Satoru Simizu,

Alex Leary, Mike McHenry,

Paul Ohodnicki

Cristina Bormio-Nunes,

Fábio Martins Cardoso

Zhiqiang $\mathrm{Fu}$,

Benjamin E. MacDonald,

Todd C. Monson, Baolong Zheng,

Weiping Chen, Enrique J. Lavernia

Eric D. Langlois, Todd C. Monson, Dale L. Huber, John Watt 